\title{
The descending thoracic aorta morphological characteristics
}

Faculty of Medicine, “Ovidius” University, Constanta

\begin{abstract}
Our study was conducted by consulting angioCT sites made on a CT GE LightSpeed VCT64 Slice CT and a CT GE LightSpeed 16 Slice CT, following the path and relationships of the descending thoracic aorta against the vertebral column, outside diameters thereof at the thoracic vertebrae T4, T7, T12 and posterior intercostal arteries characteristics. The origin of of the descending thoracic aorta we found most commonly on the left flank of the lower edge of the vertebral body T4, but I have encountered cases where it had come above the lower edge of $\mathrm{T} 4$ on level of intervertebral disc T4-T5 or even at the upper edge of T5 vertebral body. At thoracic vertebra $\mathrm{T} 4$, on a total of 30 cases, the descending thoracic aorta present a diameter of 20.0 to $32.6 \mathrm{~mm}$, values that correspond to male gender and to females diameter ranging from 25.5 to $27,4 \mathrm{~mm}$. At level of $\mathrm{T} 7$ thoracic vertebra, thoracic aorta present a diameter of 19.6 to $29.5 \mathrm{~mm}$, values found in men, in women the diameter being from 21.9 to $25.2 \mathrm{~mm}$. At thoracic vertebra $\mathrm{T} 12$, on a total of 27 cases, the descending thoracic aorta present a diameter of 17.6 to $27.7 \mathrm{~mm}$, in males the diameter was from 17.6 to $27.7 \mathrm{~mm}$ and females diameter ranging from 21.1 to 25.2 . The length of the descending thoracic aorta was from 18.40 to $19.41 \mathrm{~cm}$.
\end{abstract}

Keywords: descending thoracic aorta - morphological characteristics

\section{Sajid Malik}

Faculty of Medicine, University “Ovidius" of Constanta University Street, No. 1, Campus B

Constanta, Romania

\section{Introduction}

Descending thoracic aorta extends from the aortic arch (which it continues) and aortic hiatus of the diaphragm at level of T12 vertebra $[1,2,3,4,5]$ corresponding to the front of T10 [6], level that continues with the abdominal descending aorta. She enters the posterior mediastinum at the $\mathrm{T} 4$ vertebra and describes a trajectory which is vertically downward as a whole, being slightly inferior oblique and to the right, then, first at a distance of $2-3 \mathrm{~cm}$ midline, progressive approach to become median and prevertebral at the T12 vertebra. It thus appears to run in a spiral around the thoracic esophagus. Descending thoracic aorta as a whole describe a curve with the concavity anteriorly up to the height of the T10 vertebra and then with a posterior concavity down to the aortic orifice of the diaphragm in the T12 vertebra [3]. After [4], thoracic aorta starts in the second curvatures, after the origin of the left subclavian artery, after the Isthmus of Stahel, located entirely at the level of posterior to mediastinum. It has an average length of $25 \mathrm{~cm}$ and has an almost constant caliber, $18-20 \mathrm{~mm}$ due to the absence of collaterals with voluminous caliber [4]. [7] finds in males, from 23.9 to $29.8 \mathrm{~mm}$ diameters and in women from 24.5 to $26.4 \mathrm{~mm}$. The first 3 intercostal arteries arising from the superior intercostal artery, branch of the subclavian artery, and the next 9 arise directly from the back of the descending thoracic aorta. They are moving horizontally out where, for the first three superior, oblique and superolateral pass on the anterolateral faces of the thoracic vertebral 
bodies to get into the intercostal space which they are intended, accompanied by satellite vein which is constant suprajacent $[1,3,6]$. By [8], in subjects with elongated, narrow thorax (sagittal type aortic arch), thoracic aorta is sensitive rectilinear being applied on the front of the dorsal rachis. In contrast, in subjects with chest wide and flared (front type aortic arch), aorta is located on the left side of the dorsal rachis, not moving toward the midline, only inferior to the posterior mediastinum, most commonly in the aortic hiatus of the diaphragm.

\section{Materials and methods}

Our study was conducted by consulting angioCT sites made on a GE LightSpeed CT VCT64 Slice CT Scanner and a GE LightSpeed 16 Slice computer CT, endowment Emergency County Hospital "St. Andrei" in Constanta. They were followed: the descending thoracic aorta path and relations with vertebral column, its outer diameter at the level of thoracic vertebrae T4, T7, T12 and posterior intercostal arteries characteristics. The morphological characteristics of the descending thoracic aorta were obtained by analyzing a number of 34 angioCT sites executed on persons without disorders of the arteries, 21 were males and 13 females.

\section{Results}

The origin o of the descending thoracic aorta we found most commonly on the left flank of the lower edge of the vertebral body T4, but I have encountered cases where it had come above the lower edge $\mathrm{T} 4$ on level of intervertebral disc T4-T5 or even at the upper edge of T5 vertebral body.

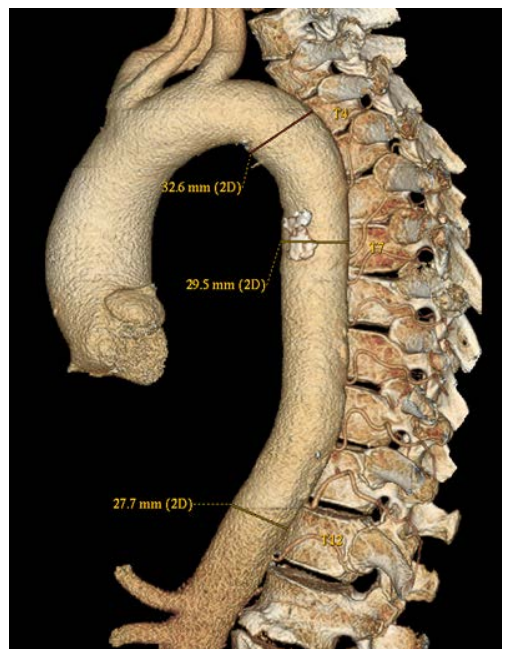

Fig. 1. Descendent aorta with origin at the inferior margin of T4 vertebra. The diameters are: T4-32.6 $\mathrm{mm} ; \mathrm{T7}-29.5 \mathrm{~mm} ; \mathrm{T12}-27.7 \mathrm{~mm}$. From the origin the posterior intercostal arteries have an ascendent tract and in their traject to the conjugation hole is horizontal on the superjacent vertebral body (male)

At thoracic vertebra T4, on a total of 30 cases, the descending thoracic aorta present a diameter of 20.0 to $32.6 \mathrm{~mm}$, the difference between minimum and maximum diameter being $12.6 \mathrm{~mm}$, these dimensions also correspond to those seen in males. In 15 cases ( $50 \%$ of cases) diameter measure 20.0 to $25.5 \mathrm{~mm}$, in 13 cases $(43.33 \%$ of cases) diameter was between 26.5 to $28.4 \mathrm{~mm}$, and in 2 cases (6 $67 \%$ of cases) diameter have $32.5 \mathrm{~mm}$ and $32.6 \mathrm{~mm}$. In males in 10 cases ( $47.62 \%$ of cases) have a diameter between 26.5 to $28.4 \mathrm{~mm}$, in 9 cases $(42.86 \%$ of cases) diameter was between 26.5 to $28.4 \mathrm{~mm}$. In women descending thoracic aorta diameter at the level of T4 vertebra I found it between 25.5 to $27.4 \mathrm{~mm}$, thus showing a difference of $1.9 \mathrm{~mm}$.

At T7 thoracic vertebra on a total of 30 cases presents thoracic aorta diameters of 19.6 to $29.5 \mathrm{~mm}$, between the minimum and maximum diameter being a difference of $9.9 \mathrm{~mm}$. In 10 cases $(33.33 \%$ of cases) the diameter was between 19.6 to $21.9 \mathrm{~mm}$, in 18 cases $(60 \%$ of cases) between 23.0 to $25.6 \mathrm{~mm}$, and in 2 cases $(6.67 \%$ of cases) the diameter, have 28.7 $\mathrm{mm}$ and $29.5 \mathrm{~mm}$. 


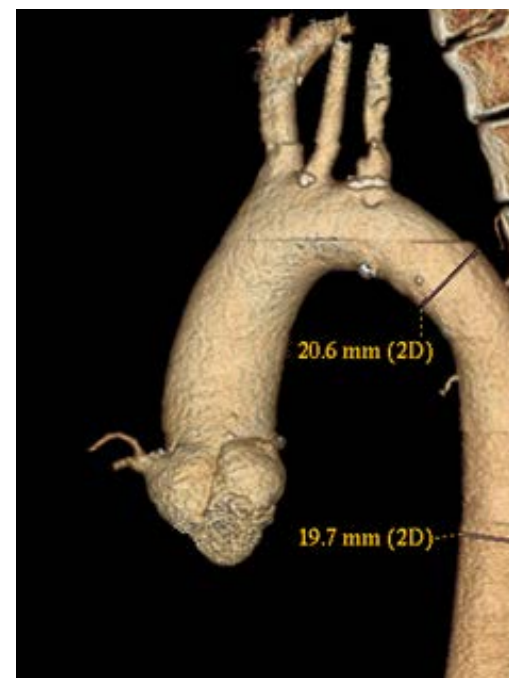

Figure 2 Descendent thoracic aorta with the origin at the superior margin of T5 vertebra. The diameters are at T4 $20.16 \mathrm{~mm}$; T7 - $19.7 \mathrm{~mm}$; T12 - $17.6 \mathrm{~mm}$ (male)

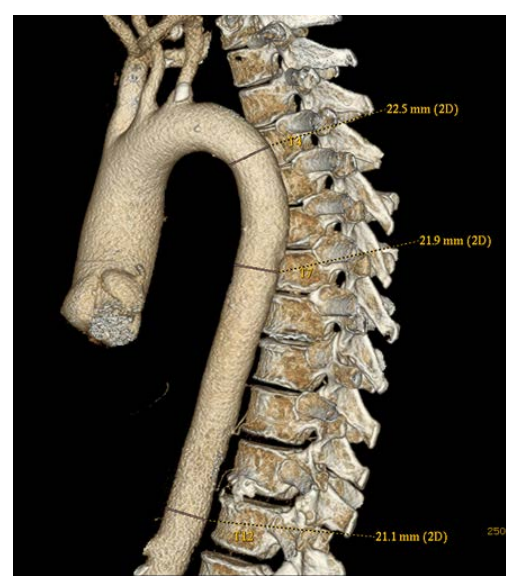

Figure 3 Thoracic descendent aorta diameters in females are at T4 - $22.5 \mathrm{~mm} ; \mathrm{T} 7-21.9 \mathrm{~mm} ; \mathrm{T12}-21.1 \mathrm{~mm}$

In males the aortic diameter, was between 19.6 to $29.5 \mathrm{~mm}$, in 7 cases ( $33.33 \%$ of cases) having 19.6 to $21.9 \mathrm{~mm}$, in 12 cases 23.0 to $25.6 \mathrm{~mm}$, and in two cases ( $9.52 \%$ of cases), $28.7 \mathrm{~mm}$ and $29.5 \mathrm{~mm}$. The aortic diameter in women ranged, at the $\mathrm{T} 7$ vertebra, between 21.9 to $25.2 \mathrm{~mm}$, so a difference of $3.3 \mathrm{~mm}$.

At the T12 thoracic vertebra level (at the level of the aortic diaphragmatic hiatus), on a total of 27 cases, the descending thoracic aorta present a diameter of 17.6 to $27.7 \mathrm{~mm}$, the difference between minimum and maximum diameter being $10.1 \mathrm{~mm}$. Most commonly, in 15 cases ( $55.56 \%$ of cases) have the diameter, from 23.1 to $25.2 \mathrm{~mm}$, in 10 cases $(37.04 \%$ of cases) from 17.6 to $21.9 \mathrm{~mm}$ and in 2 cases $(7.41 \%$ of cases) have $27.0 \mathrm{~mm}$ and $27.7 \mathrm{~mm}$. In males in 4 cases $(22.22 \%$ of cases) the diameter ranged from 17.6 to $27.7 \mathrm{~mm}$, in 12 cases ( $66.67 \%$ of cases) being 17.6 to $21.9 \mathrm{~mm}$, and in two cases (11.11\% of cases) with $27.0 \mathrm{~mm}$ and $27.7 \mathrm{~mm}$. The aortic diameter at the T12 vertebra, in women ranged between 21.1 to $25.2 \mathrm{~mm}$, so between the two diameters there is a difference of $3.3 \mathrm{~mm}$.

\section{Discutions}

In the cases we studied, we found the descending thoracic aorta origin similar to those mentioned by $(2,5,9)$, the lower edge of the body T4 vertebra, $[1,3,4,8]$ finding it latero-vertebral T4 without specifying the origin level. Only [6] mentions the possibility of the origin at the T3 vertebra.

By averaging the descending thoracic aorta diameters in the three vertebrae (T4, T7 and T12), I found that it ranged from 19.7 to 29.93 $\mathrm{mm}$, characteristic of male gender, to females being between $22.83-25.93 \mathrm{~mm}$. It notes that the minimum diameter is smaller in males, with $3.10 \mathrm{~mm}$, aspect found by [7] that finds this difference but bigger, being $5.3 \mathrm{~mm}$. Compared with the results of [7], male gender difference found by us $(10.23 \mathrm{~mm})$ at the minimum diameter is higher by $4.33 \mathrm{~mm}$ from it, which found $5.9 \mathrm{~mm}$. In women, we found a difference of the minimum diameter by $3.1 \mathrm{~mm}$, greater than the difference found by [7] with $1.2 \mathrm{~mm}, 1.9 \mathrm{~mm}$ it finds. At the level of maximum diameter, it is higher in males, than in females, a difference of $4.0 \mathrm{~mm}$, [7] finding that difference of $3.4 \mathrm{~mm}$, the difference found so close to us. [4] finds thoracic aortic diameter between 18 to $20 \mathrm{~mm}$, the minimum diameter being smaller than that found by us with $1.07 \mathrm{~mm}$ in males and $4.83 \mathrm{~mm}$ in females. The maximum diameter found by us is higher by $9.93 \mathrm{~mm}$ in males and 5.93 $\mathrm{mm}$ in females. [4] states that the descending thoracic aorta has a diameter almost constantly because of 
his level do not come off voluminous branches. We have found that there is a progressive decrease of its diameter in supero-inferior path, reaching as from origin (T4 vertebra) down to the diaphragmatic hiatus decreasing diameter being between 6.12 to $16.92 \%$, the most frequently encountered decreasing diameter ranging from 14.12 to $16.92 \%$ (57.14\% of in cases). Between T4-T7 vertebrae decreasing diameter is 1.18 to $16.6 \%$, and between $\mathrm{T} 7-\mathrm{T} 12$ we found a decreasing diameter from 3.65 to $13.10 \%$.

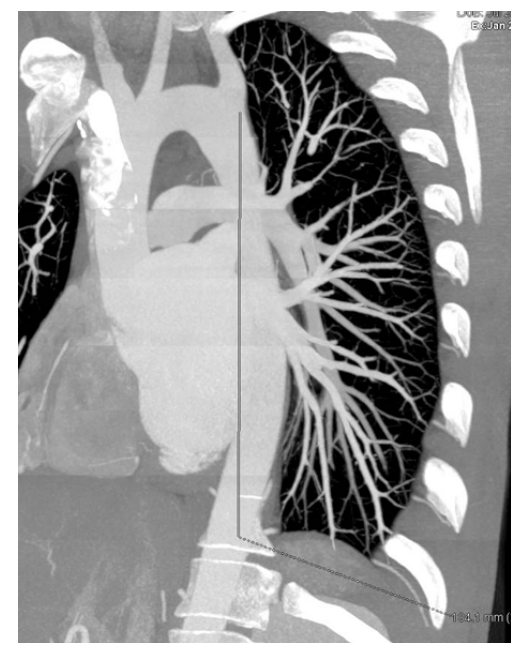

Figure 4 The lenghs of the thoracic descendent aorta: $18.41 \mathrm{~cm}$

In the cases we studied found the length of the descending thoracic aorta between 18.40 to $19.41 \mathrm{~cm}$, much lower (between 5.59 to $6.60 \mathrm{~cm}$ ) than the length given by [4], which finds it $25 \mathrm{~cm}$.

By all descending thoracic aorta collaterals I followed, only posterior intercostal arteries whose diameters I found it between 1.4-2.1 mm, finding them the right intercostal arteries most commonly thicker $(1-3 \mathrm{~mm})$ than the left, sometimes the two arteries may have a equal diameter, [6] noting that the intercostal arteries are almost equal to the two sides of the body. I found that the first (most often) or sometimes the first 2 intercostal arteries have a very oblique trajectory, being closer to the vertical. The following intercostal arteries (up to intercostal 4-5) having an oblique trajectory supero-lateral aspect signaled by $[1,3,6]$.

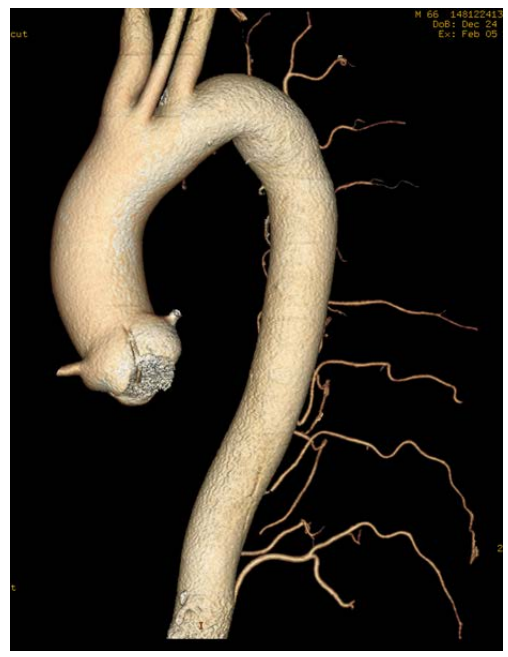

Figure 5 The first two intercostal arteries have the origin in the aortic arch, having a vertical tract. The second and the last intercostal arteries have the origin in a comon trunc. The last intercostal arteries initially have an ascendent tract

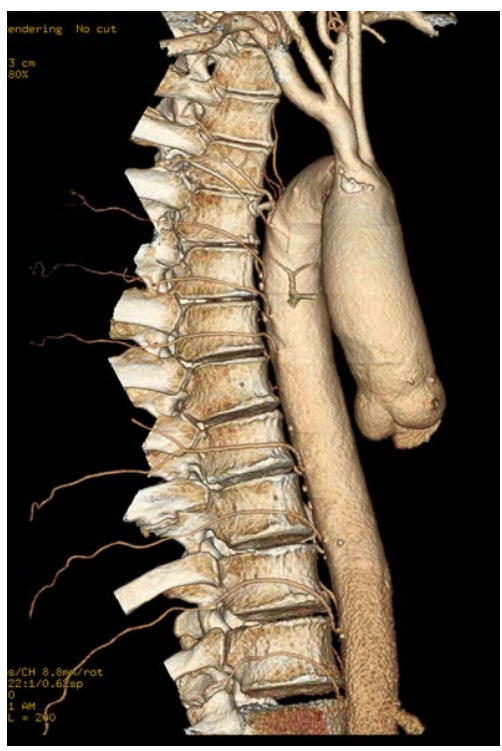

Figure 6 the intercostal arteries have the origin at the level of the intervertebral disks or caudal relative to these, have an ascendent tract and become transversal at the level of the superjacent vertebral body. The first 2 intercostal arteries have the orifin at the aortic arch level, the first intercostal artery having a vertical tract 




Figure 7 The posterior intercostal arteries, the pairs have the origin at the same level or with a small offset

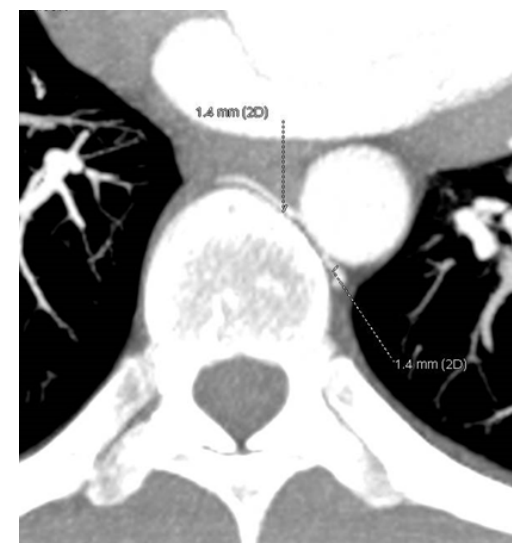

Figure 8 Posterior intercostal arteries, right and left, have equal diameters: $1.4 \mathrm{~mm}$

The next intercostal arteries down to 10th intercostal artery have a horizontal trajectory, frequently subcostal artery and 10-11th intercostals having a infero-lateral trajectory as the direction of the accompany rib. Intercostal arteries arise pair at the same level, on the back of the aorta [5] we finding that sometimes the left intercostals origin may be slightly above located. We have found that may exist common trunks for two adjacent intercostal arteries, variant reported by [6]. I have encountered cases where superior intercostal arteries originate in the aorta to the center line of the rear face of the aorta artery or cases where origin is in the level of intervertebral discs and in their path to the intercostal space can cross the body for the underlying vertebra.

\section{Conclusions}

Morphometry of the descending thoracic aorta is directly related to gender, age and especially morphological type of the individual, in females the aorta sizes being lower than in males, and once we age we know that there is an easy and widespread expansion of the aorta. On sagittal type subjects, thoracic aorta is longer but has a lower caliber, on frontal type subjects, thoracic aorta is shorter with a higher caliber. Also, depending on the morphological type differ also the artery path, in sagittal type the aorta being substantially rectilinear [8]. Modern imaging techniques lead to a correct and early aortic disorders diagnosis even in emergency conditions, which changed the management of patients and lead to early decision [10]. The study carried out by us has importance not only morphological, but also for cardiovascular surgeon in the thoracic descending aorta approach, especially for aneurysm. Although rare in the level of the descending thoracic aorta, the aneurysm of this segment gives a mortality of 1.5$2.5 \%$ of the cases [10] and after [11], the death rate is from $5 \%$ to $14 \%$.

\section{References}

1. Rouvière, H. \& Delmas, A. (1997). Anatomie Humaine. Déscriptive topographique et fonctionnelle. Tome 2. Tronc. 14-édition. (pp. 172-177). Paris: Ed. Masson.

2. Standring, S. (2005). Gray's Anatomy. The Anatomical Basis of Clinical Practice. (pp. 1023-1024). Ed. Elsevier Churchill Livingstone

3. Bouchet, A. \& Cuilleret, J. (1991). Anatomie topographique, descriptive et fonctionnelle. Tome 2. Le cou. Le thorax. (pp. 959-965). Paris: Ed. SIMEP

4. Nguyen, H. (1996). L'artère thoracique. In: Anatomie clinique. Le Tronc, Eds. Chevre, 
J.P., (pp. 177-190). Ed. Springer-Verlag, Paris

5. Kamina, P. (2002). Précis d'anatomie clinique. (pp. 134-137). Tome II. Ed. Maloine, Paris.

6. Testut, L. (1924) Traité d'anatomie humaine. Angéiologie. Livre IV. (pp. 110-117; 185-190). Ed.Gaston Doin, Paris,

7. Vega, J., Gonzalez, D., Yankovic, W., Oroz, J., Guaman, R. \& Castro, N. (2014). Aneurismas de la aorta torácica: Historia natural, diagnóstico y tratamiento. Revista chilena de cardiología. 33, 127-135.

8. Paturet, G. (1958). Traité d'anatomie humaine, Tome III, (pp. 221-230). Ed. Masson, Paris.

9. Moore, L.K. \& Dalley, F.A. (2001). Anatomie médicale. Aspects fondamentaux et applications cliniques. (pp. 151-152). Ed. De Boeck Université, Bruxelles
10. Pape, L.A., Tsai, T.T., Isselbacher, E.M., Oh, J.K., O'Gara P, T., Evangelista, A., Fattori, R., Meinhardt, G., Trimarchi, S., Bossone, E., Suzuki, T., Cooper, J.V., Froehlich, J.B., Nienaber, C.A. \& Eagle, K.A. (2007). Aortic diameter $>$ or $=5.5 \mathrm{~cm}$ is not a good predictor of type A aortic dissection: observations from the International Registry of Acute Aortic Dissection (IRAD). Circulation. 116(10), 1120-1127. doi: 10.1161/circulationaha.107.702720

11. Isselbacher, E.M. (2005). Thoracic and abdominal aortic aneurysms. Circulation. 111(6), 816-828. doi: 10.1161/01.CIR.0000154569.08857.7A

12. $* * * * * * * *$ (1988). Terminologia Anatomica. International Anatomical Terminology. Federative Committee on Anatomical Terminology 1988. Stuttgart: Thieme Verlag 